\title{
Efficacy of switching from adefovir to tenofovir in chronic hepatitis $B$ patients who exhibit suboptimal responses to adefovir-based combination rescue therapy due to resistance to nucleoside analogues (SATIS study)
}

\author{
Hye Won Lee ${ }^{1}$, Jun Yong Park ${ }^{1,2}$, Beom Kyung Kim ${ }^{1,2}$, Moon Young Kim ${ }^{1,3}$, Jung Il Lee ${ }^{1,4}$, Young Suk Kim ${ }^{1,5}$, \\ Ki Tae Yoon ${ }^{1,6}$, Kwang-Hyub Han ${ }^{1,2}$, and Sang Hoon $\mathrm{Ahn}^{1,2}$ \\ 'Department of Internal Medicine, ${ }^{2}$ Institute of Gastroenterology, Yonsei University College of Medicine, Seoul; ${ }^{3}$ Wonju Severance \\ Christian Hospital, Yonsei University Wonju College of Medicine, Wonju; ${ }^{4}$ Gangnam Severance Hospital, Yonsei University College of \\ Medicine, Seoul; ${ }^{5}$ Soonchunhyang University Bucheon Hospital, Soonchunhyang University College of Medicine, Bucheon; ${ }^{6}$ Pusan \\ National University Yangsan Hospital, Pusan National University School of Medicine, Yangsan, Korea
}

Background/Aims: It remains to be determined whether switching from adefovir (ADV) to tenofovir (TDF) provides better virological outcomes in patients exhibiting suboptimal responses to ADV plus nucleoside analogue (ADV+NA) therapy for NA-resistant chronic hepatitis B (CHB).

Methods: In this prospective trial, patients who showed partial responses (defined as serum hepatitis B virus [HBV] DNA $>60 \mathrm{IU} / \mathrm{mL}$ ) to ADV+NA therapy for NA resistance were randomly allocated to receive TDF plus NA (TDF+NA group, $n=16$ ) or to continue their current therapy (ADV+NA group, $n=16$ ). The primary end point was the proportion of patients with complete virological response (CVR, defined as serum HBV DNA $<60 \mathrm{IU} / \mathrm{mL}$ ) at 48 weeks.

Results: The median age was 52 years (16 men), and 28 were positive for hepatitis B e antigen (HBeAg). The baseline characteristics did not differ significantly between the two groups. The proportion with CVR was significantly higher in the TDF+NA group than in the ADV+NA group at 24 weeks $(81.3 \%$ vs. $25.0 \%, P=0.001)$ and 48 weeks $(87.5 \%$ vs. $37.5 \%$, $P=0.002$ ). Furthermore, a decrease in the serum HBV DNA level of $>2 \log _{10} \mathrm{IU} / \mathrm{mL}$ was more likely in the TDF+NA group at both 24 and 48 weeks ( $68.8 \%$ vs. $56.3 \%, P=0.014$ vs. $81.3 \%$ vs. $56.3 \%, P=0.001$, respectively). During the follow-up, the rate of HBeAg seroconversion was higher in the TDF+NA group than the ADV+NA group ( $12.5 \%$ vs. $6.25 \%, P=0.640)$, as was that for the hepatitis $B$ surface antigen ( $6.25 \%$ vs. $0 \%, P=0.080)$. No serious adverse events due to antiviral agents occurred.

Conclusions: In patients exhibiting suboptimal responses to ADV+NA therapy for NA-resistant CHB, switching from ADV to TDF might provide better virological outcomes. (Clin Mol Hepatol 2016;22:443-449)

Keywords: Adefovir; Chronic hepatitis B; Complete virological response; Suboptimal response; Tenofovir

\footnotetext{
Abbreviations:

$A D V$, adefovir dipivoxil; $A L T$, alanine aminotransferase; $C H B$, chronic hepatitis $B$; HBeAg, hepatitis B e antigen; CVR, complete virological response; HBV, hepatitis $B$ virus; HCC, hepatocellular carcinoma; HBsAg, hepatitis B surface antigen; IQR, interquartile range; LAM, lamivudine; NA, nucleoside analogue; RFMP, restriction fragment mass polymorphism; TDF, tenofovir disoproxil fumarate; VR, virological response
}

Corresponding author : Sang Hoon Ahn

Department of Internal Medicine, Yonsei University College of Medicine, 50-1 Yonsei-ro, Seodaemun-gu, Seoul 03722, Korea

Tel: +82-2-2228-1936, Fax: +82-2-393-6884

E-mail:ahnsh@yuhs.ac 


\section{INTRODUCTION}

Chronic hepatitis B (CHB) infection is a leading cause of development of liver cirrhosis and/or hepatocellular carcinoma (HCC). Since the high serum HBV DNA level indicating active virus replication has been identified as an independent risk factor for development of cirrhosis and HCC in two large-scale studies, ${ }^{2,3}$ the treatment of goal in the current era of antiviral therapy is sustained suppression of viral replication through antiviral therapy. ${ }^{4}$ For this goal, recent antiviral agents with good potency and safety, tolerability, and convenience to increase adherence was continuously developed.

Since lamivudine (LAM), a first-generation oral nucleoside analogue (NA) were available in 1998, the paradigm of CHB treatment has been changed substantially. Actually, the use of LAM had significantly reduced the incidence of hepatic events in patients with advanced fibrosis or compensated cirrhosis. ${ }^{5}$ However, such a clinical benefit may be substantially offset by a high rate of resistance of up to $80 \%{ }^{6,7}$ The incidence rates of telbivudine resistance were $4.4 \%$ at year 1 and $21.6 \%$ at year 2 in $\mathrm{HBeAg}$ positive CHB patients, and $2.7 \%$ at 1 year and $8.6 \%$ at year 2 in HBeAg negative CHB patients. ${ }^{8,9}$ Virological breakthrough with rtM204V/I mutations occurred in 4\% at year 1 and $20 \%$ at year 2 in CHB patients with clevudine. ${ }^{10}$ For those who developed resistance to NAs including LAM, telbivudine or clevudine, the adverse effects of $\mathrm{HBV}$ drug resistance mutations may be overcome by the addition of adefovir dipivoxil (ADV). ${ }^{11}$ However, according to the study conducted in Korea, complete virological response (CVR) was achieved only in $32.4 \%$ during ADV and LAM combination (referred as ADV+NA) therapy in LAM-resistant patients. ${ }^{12}$ In another study, cumulative rates of CVR were $29.9 \%$ at 1 year and $86.9 \%$ at 5 years by ADV+NA therapy. ${ }^{13}$ Therefore, for patients who did not achieve CVR during ADV+NA therapy for NA-resistant strains, appropriate alternative regimens to achieve the better CVR rates should be required based upon the current paradigm of $\mathrm{CHB}$ treatment.

On the other hand, tenofovir disoproxil fumarate (TDF), a very potent antiviral agent with a high genetic barrier, showed the excellent virologic responses in treatment-naïve patients and even in patients with genotypic resistance. ${ }^{14-16}$ However, for patients with suboptimal response despite ADV-based rescue therapy, there have been only few retrospective reports regarding the antiviral efficacy of TDF-based therapy, so far. Recently, Cho et al. ${ }^{17}$ showed the overall virological responses of about $85 \%$ through TDF-based rescue therapy monotherapy in CHB patients with sub- optimal responses to rescue therapy for prior LAM resistance Furthermore, Yang et al. ${ }^{18}$ compared the antiviral efficacy between switching to TDF monotherapy and continuous add-on therapy, showing the superior outcomes of TDF monotherapy.

Here, in this prospective study, we aimed to directly compare the antiviral efficacy between switching to TDF and NA combination (referred as TDF+NA) therapy and continuation of current ADV+NA therapy among patients who showed suboptimal response to ADV+NA therapy for NA-resistant CHB.

\section{MATERIAL AND METHODS}

\section{Study subjects}

Between March 2012 and February 2014, patients were enrolled from five tertiary referral hospitals in Korea. Patients with CHB (defined as positive serum hepatitis B surface antigen [HBsAg] test for at least 6 months) were considered eligible for enrolment. Inclusion criteria were as follows; 1) confirmed mutations in the hepatitis $B$ virus (HBV) polymerase gene that confers resistance to NAs (LAM $100 \mathrm{mg}$, telbivudine $600 \mathrm{mg}$, entecavir 0.5 $\mathrm{mg}$ or clevudine $30 \mathrm{mg} / \mathrm{d}$ orally), 2) suboptimal response (defined as serum HBV DNA level $\geq 60 \mathrm{lU} / \mathrm{mL}$ ) after ADV $10 \mathrm{mg} / \mathrm{d}$ orally+NA therapy for at least 6 months. Exclusion criteria were as follows; 1) less than 20 years old, 2) previous or current history of HCC, 3) prior treatment with antiviral agent other than NAs and/or ADV, 4) decompensated liver disease, 5) co-infection with other viral hepatitis or other current liver diseases, 6) ADV resistance mutation, 7) concurrent systemic corticosteroids or other immunosuppressive agents, 8) history of alcohol or substance abuse, 9) prior organ transplantation, and 10) a history of malignancy within 3 years. The analysis in this study is based on intention-to-treat.

This study was approved by independent institutional review boards and conformed to the ethical guidelines of the $1975 \mathrm{Hel}$ sinki declaration. Written informed consent was obtained from patients or responsible family members.

\section{Study designs}

This study was a multi-center, randomized, open-label trial (ClinicalTrials.gov, ID number NCT01595633). Patients were randomly allocated at 1:1 to receive TDF (300 mg q.d)+NA therapy (TDF+NA group) $(n=16)$ or to continue current ADV+NA therapy 
(ADV+NA group) ( $n=16)$. Patients were followed-up for 48 weeks after randomization. Randomized patients were evaluated at baseline and week 24 and 48 (Fig. 1). At each visit, complete blood counts, biochemistry, and prothrombin time were assessed.

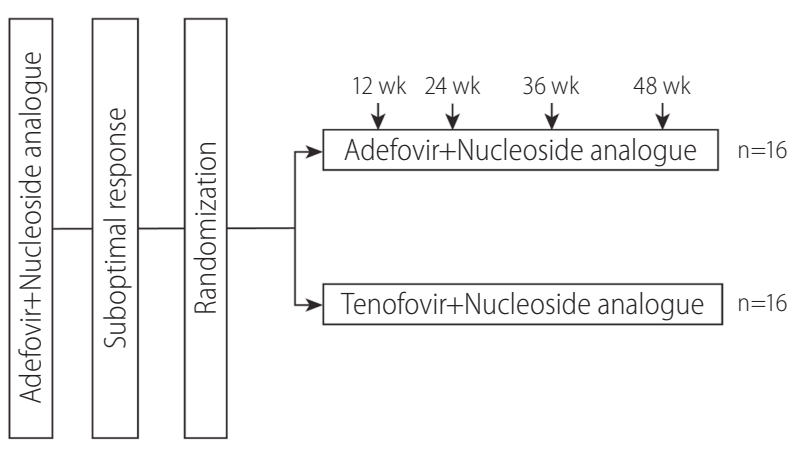

Figure 1. Recruitment algorithm for the study population.
HBV DNA level was checked at baseline and week 24, and 48, using a polymerase chain reaction assay (Amplicor HBV Monitor Test, 20 IU/mL detection limit; Roche Diagnostics, Basel, Switzerland). Resistance mutations to NAs and ADV were evaluated using restriction fragment mass polymorphism (RFMP) assays at baseline and in case of necessity. Hepatitis B e antigen ( $\mathrm{HBeAg}$ ) and anti-HBe were assessed at baseline and at week 48, using commercially available enzyme immunoassays (Abbott Laboratories). The upper limit of normal of alanine aminotransferase (ALT) was defined as $40 \mathrm{IU} / \mathrm{L}$. Occurrences of adverse events were assessed at every visit during follow-up period.

Cirrhosis was defined as follows: 1) platelet count $<100,000 / \mu \mathrm{L}$ and ultrasonographic findings suggestive of cirrhosis, including a blunted, nodular liver edge with splenomegaly (>12 cm); 2) ascites, esophageal or gastric varices, or hepatic encephalopathy; or 3) overt complications of cirrhosis.

Table 1. Baseline characteristics

\begin{tabular}{|c|c|c|c|c|}
\hline Variables & All $(n=32)$ & $A D V+N A(n=16)$ & TDF+NA $(n=16)$ & $P$-values \\
\hline \multicolumn{5}{|l|}{ Demographic variables } \\
\hline Age, years & $51.5(46.5-59.3)$ & $53.5(42.0-59.3)$ & $51.0(48.0-59.0)$ & 0.972 \\
\hline Male gender & $16(50.0)$ & $10(62.5)$ & $6(37.5)$ & 0.157 \\
\hline Cirrhosis & $12(37.5)$ & $8(50.0)$ & $4(25.0)$ & 0.144 \\
\hline \multicolumn{5}{|l|}{ Laboratory variables } \\
\hline $\mathrm{WBC}, / \mu \mathrm{L}$ & $5,130(4,263-6,008)$ & $4,945(4,048-6,008)$ & $5,150(4,400-6,280)$ & 0.718 \\
\hline Hemoglobin, g/dL & $14.0(13.0-16.0)$ & $14.5(12.3-16.0)$ & $14.0(13.0-15.8)$ & 0.215 \\
\hline Platelet, / $\mu \mathrm{L}$ & $167.0(133.0-187.0)$ & $173.0(133.0-193.0)$ & $162.0(123.0-251.0)$ & 0.739 \\
\hline PT INR & $1.0(1.0-1.0)$ & $1.0(1.0-1.0)$ & $1.0(1.0-1.0)$ & - \\
\hline Albumin, g/dL & $4.0(3.0-4.0)$ & $4.0(3.0-4.0)$ & $3.5(3.0-4.0)$ & 0.085 \\
\hline AST, IU/mL & $26.0(21.0-30.0)$ & $27.0(19.0-32.0)$ & $25.0(22.0-30.0)$ & 0.449 \\
\hline $\mathrm{ALT}, \mathrm{IU} / \mathrm{mL}$ & $26.0(22.0-35.0)$ & $26.0(23.0-39.0)$ & $25.0(16.0-34.0)$ & 0.595 \\
\hline Total bilirubin, mg/dL & $1.0(1.0-1.0)$ & $1.0(0.7-1.0)$ & $1.0(1.0-1.0)$ & - \\
\hline$A L P, I U / L$ & $71.0(55.0-151.0)$ & $66.5(50.3-144.0)$ & $72.0(59.0-163.0)$ & 0.077 \\
\hline Cholesterol, mg/dL & $163.0(148.0-184.0)$ & $159.0(146.0-181.0)$ & $168.0(149.0-202.0)$ & 0.972 \\
\hline \multicolumn{5}{|l|}{ Viral laboratory variables } \\
\hline HBV DNA, $\log _{10} I \mathrm{IU} / \mathrm{mL}$ & $4.2(3.4-5.0)$ & $4.6(3.8-5.1)$ & $3.7(3.3-4.8)$ & 0.005 \\
\hline HBe Ag positive & $28(87.5)$ & $14(87.5)$ & $14(87.5)$ & 0.593 \\
\hline \multicolumn{5}{|l|}{ Previous antivirals } \\
\hline Telbivudine & $14(43.8)$ & $5(31.3)$ & $9(56.3)$ & \\
\hline Lamivudine & $9(28.1)$ & $5(31.3)$ & $4(25.0)$ & \\
\hline Entecavir & $9(28.1)$ & $6(37.5)$ & $3(18.8)$ & \\
\hline
\end{tabular}

Values are expressed as median (interquartile range) or $n(\%)$.

ADV, adefovir dipivoxil; TDF, tenofovir disoproxil fumarate; NA, nucleoside analogue; WBC, white blood cell; PT, prothrombin time; INR, international normalized ratio; AST, aspartate aminotransferase; ALT, alanine aminotransferase; ALP, alkaline phosphatase; HBV, hepatitis B virus; HBeAg, hepatitis B e antigen. 
Table 2. Virological outcomes during the follow-up period

\begin{tabular}{lccc}
\hline & ADV+NA & TDF+NA & P-values \\
\hline Serum HBV DNA level at week 24, $\log _{10} \mathrm{IU} / \mathrm{mL}$ & $3.5(2.3-4.2)$ & $1.3(1.3-1.3)$ & 0.001 \\
\hline Serum HBV DNA level at week 48, $\log _{10} \mathrm{IU} / \mathrm{mL}$ & $3.2(1.3-4.5)$ & $1.3(1.3-1.3)$ & 0.004 \\
VR at week 48 & $6(37.5)$ & $14(87.5)$ & 0.002 \\
VR at week 24 & $4(25.0)$ & $13(81.3)$ & 0.001 \\
Decrease in serum HBV DNA level of $>$ 2 $\log _{10}$ from baseline at week 24 & $9(56.3)$ & $11(68.8)$ & 0.014 \\
Decrease in serum HBV DNA level of $>2 \log _{10}$ from baseline at week 48 & $9(56.3)$ & $13(81.3)$ & 0.001 \\
HBeAg loss & $1(6.25)$ & $2(12.5)$ & $>0.05$ \\
HBsAg loss & $0(0)$ & $1(6.25)$ & $>0.05$ \\
\hline
\end{tabular}

Values are expressed as median (interquartile range) or $n(\%)$.

ADV, adefovir dipivoxil; NA, nucleoside analogue; TDF, tenofovir disoproxil fumarate; HBV, hepatitis B virus; VR, virological response; HBeAg, hepatitis B e antigen; HBsAg, hepatitis B surface antigen.

\section{Definitions of study endpoints}

The primary endpoint was the proportion of patients with virological response (VR, defined as serum HBV DNA level <60 IU/ $\mathrm{mL}$ ). Secondary endpoints were the proportion of patients with VR at week 24, change in serum HBV DNA level from baseline at week 24 and 48, the proportion of patients with normalized serum ALT levels, HBeAg loss or seroconversion at week 48, and emergence of resistance mutation to drugs during study period.

\section{Statistical analysis}

Data are expressed as the median (interquartile range [IQR]), or n (\%) as appropriate. Differences among continuous and categorical variables were examined for statistical significance with Student's $t$-test (or Mann-Whitney test, if appropriate) and chisquared test (or Fisher's exact test, if appropriate). Paired related data were analyzed using the Wilcoxon paired test. A two-sided $P$ value $<0.05$ was considered to indicate statistical significance. Statistical analyses were performed using IBM SPSS ver. 20.0 (IBM Co., Armonk, NY, USA)

\section{RESULTS}

\section{Baseline characteristics of patients}

After eight patients were failed with screening, a total of 32 patients were analyzed for statistical analysis. The baseline characteristics of the study subjects are summarized in Table 1. The me-

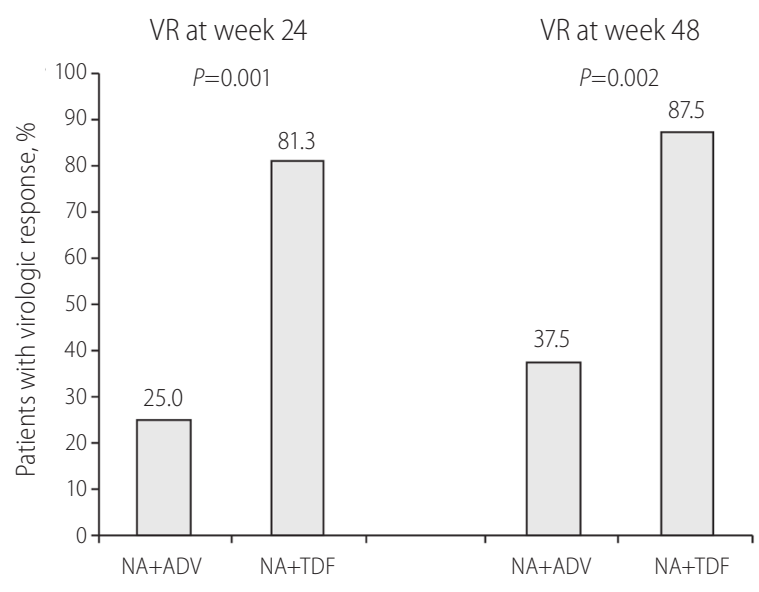

Figure 2. Proportion of patients who achieved VR at week 24 or 48 in the TDF+NA and ADV+NA groups. VR, virological response; NA, nucleoside analogue; ADV, adefovir dipivoxil; TDF, tenofovir disoproxil fumarate.

dian age was 51.5 years (men, $n=16$ ). HBeAg positivity was identified in 28 (87.5\%) patients and the median serum HBV DNA level was 4.2 (IQR 3.4-5.0) $\log _{10} \mathrm{IU} / \mathrm{mL}$. Twelve (37.5\%) patients had cirrhosis. The baseline characteristics between two groups were similar.

\section{Virological outcomes}

The efficacy of treatment in ADV+NA and TDF+NA groups are summarized and compared in Table 2 and Figure 2. During treatment, the proportions of patients with VR (defined as HBV DNA level $<60 \mathrm{IU} / \mathrm{mL}$ or 300 copies $/ \mathrm{mL}$ ) in TDF+NA group at week 24 and 48 were higher compared to those in ADV+NA group; 81.3 vs. $25.0 \%$ at week $24(P=0.001)$ and 87.5 vs. $37.5 \%$ at week 48 $(P=0.002) .57 .1 \%(16 / 28)$ of $\mathrm{HBeAg}$ positive and $25.0 \%(1 / 4)$ of 
HBeAg negative CHB patients were achieved VR at week 24. Finally, $75.0 \%$ of $\mathrm{HBeAg}$ positive and $25.0 \%$ of $\mathrm{HBeAg}$ negative CHB patients were achieved VR at week 48.

At week 24, 9 (56.3\%) patients in ADV+NA group and 11 $(68.8 \%)$ in the TDF+NA group showed the decrease in serum HBV DNA level of more than $2 \log _{10}$ from baseline $(P=0.014)$. At week 48, 9 (56.3\%) patients in ADV+NA group and 13 (81.3\%) in the TDF+NA group showed the decrease in serum HBV DNA level of more than $2 \log _{10}$ from baseline $(P=0.001)$.

There was no patient with virologic non-response (defined as decrease in serum HBV DNA level of $<1 \log _{10}$ at week 24 or 48 from baseline).

\section{Biochemical and serologic response}

The proportion of patients with normal ALT levels at week 48 did not differ significantly between two groups. Among patients with elevated ALT at baseline, all patients in ADV+NA and TDF+NA group achieved normalization of ALT at 48 week.

Among patients with positive $\mathrm{HBeAg}$, two (12.5\%) patients in ADV+NA group and one (6.25\%) in TDF+NA group showed $\mathrm{HBeAg}$ loss at week 48. Only one patient in ADV+NA group showed HBsAg loss during treatment.

\section{Safety}

Most enrolled patients were well-tolerated during treatments. The serious adverse event due to antiviral agents such as renal failure, lactic acidosis or worsening liver function was not reported. No patients required dose reduction or discontinuation of treatment due to adverse events. No patient experienced ALT flare of more than 10 times of upper normal limit. There was no patient who experienced decompensated cirrhosis or hepatocellular carcinoma during treatment period.

\section{DISCUSSION}

ADV add-on therapy has been widely used as a rescue therapy for patients with LAM-resistant $\mathrm{CHB},{ }^{19,20}$ because switching to ADV or entecavir could induce multidrug resistance. In particular, especially when TDF was unavailable, ADV add-on therapy has been regarded as a standard treatment option for those patients. However, because of the weak antiviral activity of ADV and poor susceptibility for drug-resistant viral strains, suboptimal response has been commonly observed in patients who received $A D V+N A$ therapy. ${ }^{21-23}$ The VR of ADV+NA therapy in patients with higher baseline HBV DNA was lower than those with a lower baseline HBV DNA at month 12 (7.1\% vs. $66.7 \%) .^{23}$ The persistence of suboptimal response during longterm antiviral treatment is associated with the emergence of multi-drug resistant viral strains. ${ }^{24,25}$ Thus, so far, management of a suboptimal response to antiviral therapy has been an important issue. In this clinical context, we prospectively compared the antiviral efficacy of ADV+NA and TDF+NA therapy among patients who have suboptimal response to ADV+NA therapy for NA-resistant CHB.

We found that patients with TDF+NA group are more likely to achieved VR compared to ADV+NA group after week 48 of treatment and that TDF+NA group are more likely to experience the suppression of serum HBV DNA level of $2 \log _{10}$ from baseline. Also, in terms of serological response, the proportions of $\mathrm{HBsAg}$ and $\mathrm{HBeAg}$ seroconversion were better in TDF+NA group without statistical significance.

Our study has several strengths. First, there was little research to compare between ADV+NA and TDF+NA especially for the suboptimal responder. Although the number of patients was small, the effect of switching ADV to TDF in patients who showed suboptimal response was prospectively investigated. Second, this study focused on Korean patients, most of whom have genotype $C^{26}$ Because TDF use was approved relatively late in Asia, there have been less data regarding TDF use compared to Western countries.

TDF is a potent and selective inhibitor of HBV DNA polymerasereverse transcriptase. TDF has been shown to produce potent viral suppression in large phase 3 clinical trials among treatment-naïve patients, and, to date, no TDF-specific resistance mutations have been identified. Previous study compared antiviral efficacy between ADV and TDF for NA-naïve patients, showing that patients treated with TDF had the higher proportion of suppression of serum HBV DNA level (HBV DNA <400 copies/mL) at 48 weeks ( $13 \%$ vs. $76 \%$ for HBeAg-positive patients and $63 \%$ vs. $93 \%$ for HBeAg-negative patients, respectively). ${ }^{21}$ In patients with LMV resistance, switching to ADV monotherapy results in higher rates of developing resistance to ADV than adding ADV in combination with LMV. ${ }^{27}$ Add-on combination therapy with LMV+ADV was shown to be effective in LMV resistant patients but only when initiated during the early stages of resistance development. ${ }^{28} \mathrm{Ac}-$ cording to the guideline in Korea, ${ }^{29}$ there are still several options such as LMV+ADV, LMV+TDF, ADV+NA (except LMV), TDF+NA (except LMV) or switching to TDF for patients with LMV resis- 
tance. Recently, switching to TDF monotherapy for the LMV resistance patients show effective virological suppression and does not appear to increase the risk of TDF resistance. ${ }^{18}$ TDF monotherapy induced a potent and long-lasting antiviral response in NAexperienced patients with previous treatment failure. ${ }^{15}$ So, further studies are required to compare the results of TDF+NA therapy vs. TDF monotherapy for patients with suboptimal response to $\mathrm{ADV}+\mathrm{NA}$, in terms of cost-effectiveness.

There are a few limitations of our study. First, even though conduceted in the prospective manner, this study has small sample size. It could lead to potential selection bias and weak statistical power. The original target number of this study was 124 . However, during the study period, the reimbursement policy of the National Health Insurance Service in the Republic of Korea had changed, so, it was difficult to enroll patients further. Thus, we finished the study as a pilot study. Second, follow-up duration was not long enough to observe serological outcomes between two regimens. Further studies with sufficient sample size and longer follow-up duration are needed. Third, there is no data regarding switching to TDF monotherapy from ADV+NA therapy. According to the study, ${ }^{30}$ treatment efficacy of TDF alone or TDF+LAM therapy was not different.

In conclusion, this trial demonstrated that switching from ADV+NA to TDF+NA therapy in NA-resistant CHB patients with suboptimal response resulted in superior VR. TDF+NA therapy could be a therapeutic option for patients who showed suboptimal response with ADV+NA. However, further studies with more patients should be continuously investigated for CHB patients.

\section{Funding support}

This investigator-initiated trial was supported by an unrestricted grant from Gilead, which also provided the study drug. Gilead had no role in the study design, data collection and analysis. The authors retained full responsibility for the collection and interpretation of data.

\section{Conflicts of Interest}

The authors have no conflicts to disclose.

\section{REFERENCES}

1. Ganem D, Prince AM. Hepatitis B virus infection--natural history and clinical consequences. N Engl J Med 2004;350:1118-1129.

2. Chen CJ, Yang HI, Su J, Jen CL, You SL, Lu SN, et al. Risk of hepatocellular carcinoma across a biological gradient of serum hepatitis $B$ virus DNA level. JAMA 2006;295:65-73.

3. Iloeje UH, Yang HI, Su J, Jen CL, You SL, Chen CJ, et al. Predicting cirrhosis risk based on the level of circulating hepatitis B viral load. Gastroenterology 2006;130:678-686.

4. You CR, Lee SW, Jang JW, Yoon SK. Update on hepatitis B virus infection. World J Gastroenterol 2014;20:13293-13305.

5. Liaw YF, Sung JJ, Chow WC, Farrell G, Lee CZ, Yuen H, et al. Lamivudine for patients with chronic hepatitis $B$ and advanced liver disease. N Engl J Med 2004;351:1521-1531.

6. Lok AS, Lai CL, Leung N, Yao GB, Cui ZY, Schiff ER, et al. Long-term safety of lamivudine treatment in patients with chronic hepatitis $B$. Gastroenterology 2003;125:1714-1722.

7. Lai CL, Dienstag J, Schiff E, Leung NW, Atkins M, Hunt C, et al. Prevalence and clinical correlates of YMDD variants during lamivudine therapy for patients with chronic hepatitis B. Clin Infect Dis 2003:36:687-696.

8. Lai CL, Gane E, Liaw YF, Hsu CW, Thongsawat S, Wang Y, et al. Telbivudine versus lamivudine in patients with chronic hepatitis B. N Engl J Med 2007;357:2576-2588.

9. Lai CL, Leung $N$, Teo EK, Tong M, Wong F, Hann HW, et al. A 1-year trial of telbivudine, lamivudine, and the combination in patients with hepatitis B e antigen-positive chronic hepatitis B. Gastroenterology 2005;129:528-536.

10. Gwak GY, Eo SJ, Shin SR, Choi MS, Lee JH, Koh KC, et al. A comparison of clevudine and entecavir for treatment-naive patients with chronic hepatitis B: results after 2 years of treatment. Hepatol Int 2013;7:106-110.

11. Perrillo R, Hann HW, Mutimer D, Willems B, Leung N, Lee WM, et al. Adefovir dipivoxil added to ongoing lamivudine in chronic hepatitis B with YMDD mutant hepatitis B virus. Gastroenterology 2004;126:81-90.

12. Lee HS, Park SY, Choi SY, Jung MK, Jeon SW, Cho CM, et al. Lamivudine and adefovir combination therapy in patients with lamivudine-resistant HBeAg-positive chronic hepatitis B. Korean J Med 2009;77:716-722.

13. Kim SB, Kim SU, Kim BK, Park JY, Kim DY, Ahn SH, et al. Outcome of adefovir add-on lamivudine rescue therapy of up to 5 years in patients with lamivudine-resistant chronic hepatitis B. J Gastroenterol Hepatol 2016;31:241-247.

14. Pol S, Lampertico P. First-line treatment of chronic hepatitis B with entecavir or tenofovir in 'real-life' settings: from clinical trials to clinical practice. J Viral Hepat 2012;19:377-386.

15. van Bömmel F, de Man RA, Wedemeyer H, Deterding K, Petersen J, Buggisch $P$, et al. Long-term efficacy of tenofovir monotherapy for hepatitis B virus-monoinfected patients after failure of nucleoside/ nucleotide analogues. Hepatology 2010;51:73-80.

16. European Association For The Study Of The Liver. EASL clinical practice guidelines: Management of chronic hepatitis B virus infection. J Hepatol 2012;57:167-185. 
17. Cho HJ, Kim SS, Shin SJ, Yoo BM, Cho SW, Cheong JY. Tenofovirbased rescue therapy in chronic hepatitis B patients with suboptimal responses to adefovir with prior lamivudine resistance. J Med Virol 2015;87:1532-1538.

18. Yang DH, Xie YJ, Zhao NF, Pan HY, Li MW, Huang HJ. Tenofovir disoproxil fumarate is superior to lamivudine plus adefovir in lamivudine-resistant chronic hepatitis B patients. World J Gastroenterol 2015;21:2746-2753.

19. Liaw YF, Kao JH, Piratvisuth T, Chan HL, Chien RN, Liu CJ, et al. Asian-Pacific consensus statement on the management of chronic hepatitis B: a 2012 update. Hepatol Int 2012;6:531-561.

20. Lok AS, McMahon BJ. Chronic hepatitis B: update 2009. Hepatology 2009;50:661-662.

21. Marcellin P, Heathcote EJ, Buti M, Gane E, de Man RA, Krastev Z, et al. Tenofovir disoproxil fumarate versus adefovir dipivoxil for chronic hepatitis B. N Engl J Med 2008;359:2442-2455.

22. Lee JM, Park JY, Kim do Y, Nguyen T, Hong SP, Kim SO, et al. Longterm adefovir dipivoxil monotherapy for up to 5 years in lamivudineresistant chronic hepatitis B. Antivir Ther 2010;15:235-241.

23. Ryu HJ, Lee JM, Ahn SH, Kim do Y, Lee MH, Han KH, et al. Efficacy of adefovir add-on lamivudine rescue therapy compared with switching to entecavir monotherapy in patients with lamivudine- resistant chronic hepatitis B. J Med Virol 2010;82:1835-1842.

24. Ghany MG, Doo EC. Antiviral resistance and hepatitis B therapy. Hepatology 2009;49(5 Suppl):S174-S184.

25. Locarnini S. Molecular virology and the development of resistant mutants: implications for therapy. Semin Liver Dis 2005;25(Suppl 1):9-19.

26. Bae SH, Yoon SK, Jang JW, Kim CW, Nam SW, Choi JY, et al. Hepatitis $B$ virus genotype $C$ prevails among chronic carriers of the virus in Korea. J Korean Med Sci 2005;20:816-820.

27. Yuen MF, Lai CL. Treatment of chronic hepatitis B: Evolution over two decades. J Gastroenterol Hepatol 2011;26(Suppl 1):138-143.

28. Lampertico $P$, Viganò $M$, Manenti $E$, lavarone $M$, Lunghi $G$, Colombo $M$. Adefovir rapidly suppresses hepatitis B in HBeAg-negative patients developing genotypic resistance to lamivudine. Hepatology 2005;42:1414-1419.

29. Korean Association for the Study of the Liver. KASL Clinical Practice Guidelines: Management of chronic hepatitis B. Clin Mol Hepatol 2012;18:109-162.

30. Lee YB, Jung EU, Kim BH, Lee JH, Cho H, Ahn H, et al. Tenofovir monotherapy versus tenofovir plus lamivudine or telbivudine combination therapy in treatment of lamivudine-resistant chronic hepatitis B. Antimicrob Agents Chemother 2015;59:972-978. 